\title{
Improvement of walking speed prediction by accelerometry and altimetry, validated by satellite positioning
}

\author{
O. Perrin \\ P. Terrier ${ }^{1}$ \\ Q. Ladetto ${ }^{2}$ \\ B. Merminod ${ }^{2}$ \\ Y. Schutz ${ }^{1}$ \\ Institute of Physiology, University of Lausanne, Lausanne, Switzerland \\ ${ }^{2}$ Institute of Geomatics, Swiss Federal Institute of Technology, Lausanne, Switzerland
}

\begin{abstract}
Activity monitors based on accelerometry are used to predict the speed and energy cost of walking at $0 \%$ slope, but not at other inclinations. Parallel measurements of body accelerations and altitude variation were studied to determine whether walking speed prediction could be improved. Fourteen subjects walked twice along a $1.3 \mathrm{~km}$ circuit with substantial slope variations $(-17 \%$ to $+17 \%)$. The parameters recorded were body acceleration using a uni-axial accelerometer, altitude variation using differential barometry, and walking speed using satellite positioning (DGPS). Linear regressions were calculated between acceleration and walking speed, and between acceleration/altitude and walking speed. These predictive models, calculated using the data from the first circuit run, were used to predict speed during the second circuit. Finally the predicted velocity was compared with the measured one. The result was that acceleration alone failed to predict speed (mean $r=0.4$ ). Adding altitude variation improved the prediction (mean $r=0.7$ ). With regard to the altitude/acceleration-speed relationship, substantial inter-individual variation was found. It is concluded that accelerometry, combined with altitude measurement, can assess position variations of humans provided inter-individual variation is taken into account. It is also confirmed that DGPS can be used for outdoor walking speed measurements, opening up new perspectives in the field of biomechanics.
\end{abstract}

Keywords-Human locomotion, Uphill and downhill walking, Accelerometer, Differential barometry, Differential satellite positioning

Med. Biol. Eng. Comput., 2000, 38, 164-168

\section{Introduction}

PHYSICAL ACTIVITY is a significant factor for the prevention and the treatment of cardiovascular diseases, and more generally for the improvement of public health (PATE et al., 1995). However, the exact quantity of daily activity to maintain or improve health remains to be investigated. Indeed, while it is relatively simple to assess the physical fitness or the health of a subject, it is difficult to quantify his/her daily physical activity level. Many methods have been proposed to evaluate the latter, such as questionnaires or doubly labelled water, but all of them have limitations (SCHUTZ and DEURENBERG, 1996).

Activity monitors using accelerometric sensors, available since the early 1980s, are based on simple principles: every human movement requires accelerations and decelerations of the trunk or other body segments. By recording these accelerations, the intensity of physical activity can be evaluated. The linear relationship between the integral of the modulus of body

Correspondence should be addressed to Dr Y. Schutz; email: yves.schutz@iphysiol.unil.ch

First received 11 October 1999 and in final form 4 January 2000

(C) IFMBE: 2000 acceleration and energy expenditure induced by physical activity is well documented (MONTOYE et al., 1983, MEIJER et al., 1989, ESTON et al., 1998).

Walking is of major importance in disease prevention and rehabilitation (HAKIM et al., 1998). It constitutes one of the most important contributors to total daily energy expenditure (ALMERAS et al. 1991). Therefore, many studies have attempted to test the accuracy of accelerometry for assessing walking speed and the related energy expenditure. Good correlation was found between walking speed and the integral of the modulus of body acceleration in $0 \%$ slope conditions (BALOGUN et al. 1989). Under variable uphill or downhill conditions, however, prediction of speed or energy expenditure is not possible (MELANSON and FREEDSON, 1995, TERRIER et $a l ., 1999)$. This is because the classical accelerometric methods can assess velocity variation and induced energy cost, but do not allow recording of the mechanical work carried out with or against gravity.

However, a good linear correlation was found between energy expenditure and respectively walking speed and body acceleration when the incline was kept constant on a treadmill, which could make possible the prediction of speed or energy cost of walking when the incline is assessed by an independent method (TERRIER et al., 1999). The barometer, sensitive to 
altitude variation, seemed to be an ideal device to predict terrain inclination during human locomotion. Moreover, because walking speed depends also upon incline variation (steep terrain obliges everyone to reduce velocity), altitude variation measurement could probably also improve speed prediction when combined with accelerometry.

Until now, all experiments concerning accelerometry and walking speed have been done in laboratory conditions on a treadmill, because no method was available to measure, with sufficient precision, the instantaneous speed of a human under totally unconstrained conditions. GPS (Global Positioning System) is a satellite localisation system developed by the US Department of Defence (DoD). It is used everywhere on Earth to determine absolute code position with an accuracy of about $100 \mathrm{~m}$ in planimetry and $200 \mathrm{~m}$ in altimetry. This system is widely used in navigation applications. The localisation of humans using GPS appears promising, even if it has not been used for that purpose until recently (SCHUTZ and CHAMBAZ, 1997). Using two receivers (one as a fixed base station and the other as a moving antenna (rover)) allows relative positions to be calculated with centimetre accuracy by measuring observable phase. This is an accurate and efficient method to determine someone's walking speed (LEICK, 1995). For a $30 \mathrm{~m}$ distance, the relative mean speed error is about $0.03 \%$ $\left(0.0015 \mathrm{~km} / \mathrm{h}^{-1}\right.$ for someone walking at $\left.5 \mathrm{~km} / \mathrm{h}^{-1}\right)$. The weight of the equipment becomes ever smaller with technological improvements, making this technique increasingly convenient in the field of physiology and biomechanics.

The aim of the study was to test whether combination of the measurement of altitude variation using differential barometry with the measurement of body acceleration could improve the prediction of walking speed, so as to assess energy expenditure when walking under totally unconstrained conditions. In parallel, we tested whether the altitude variation was correlated to the slope of the terrain, because this also is a crucial parameter for the energetics of locomotion.

\section{Methods}

Fourteen subjects, nine men and five women, aged between 21 and 28 participated in the study after providing informed consent. All were healthy and non-obese persons. Subjects characteristics were (mean $\pm \mathrm{SD}$ ): age: $24.6 \pm 2.4$ years; weight: $73.9 \pm 11.9 \mathrm{~kg}$ (with the weight of the devices); height: $174 \pm 9 \mathrm{~cm}$; body mass index (BMI): $21.7 \pm$ $2.5 \mathrm{~kg} \mathrm{~m}^{-2}$ (without the weight of the devices).

The study took place in the vicinity of Chexbres, a village close to Lausanne, in the Lavaux vineyards along Lake Geneva (Switzerland). The site chosen was situated at a mean altitude of $540 \mathrm{~m}$ and offered a very tortuous topography. The tests took the form of a circuit which the subjects had to walk twice, once in each direction. Subjects had to walk naturally, i.e. at their own pace and without external constraints. The total length of one run was $1310 \mathrm{~m}$ (Fig. 1) and the overall height difference was $67 \mathrm{~m}$. There were flat sections and the slope exceeded $17 \%$ for some sections. The circuit was divided into 36 sections of constant slope but of different size, according to a previous topological measurement.

Precise positioning of the subjects was measured with two Leica System 500 double frequency GPS receivers, measuring at a $5 \mathrm{~Hz}$ rate. It was possible to perform a differential carrier phase localisation between the fixed base station and the antenna mounted on the walking person (rover). The results were computed in post-processing mode and the ambiguities were solved on-the-fly using Leica's SKI-Pro software. With this up-to-date system, an accuracy of one centimetre for every position in planimetry and about two centimetres in altimetry was expected. This was the reason why this method was used as golden standard. Distance travelled was obtained by adding all $5 \mathrm{~Hz}$ positions during the selected time. Mean speed $(1 \mathrm{~Hz})$ was obtained by dividing this distance by the time difference, also provided by the GPS device.

To measure body acceleration, a single-chip capacitive accelerometer ${ }^{*}$ was used, which measured body accelerations over a range of $10 \mathrm{~g}$ (from -5 to $+5 \mathrm{~g}$ ) on one axis (anteroposterior). A band-pass filter was designed to select frequencies between $0.2 \mathrm{~Hz}$ and $20 \mathrm{~Hz}$. This range included the frequencies of human motion and excluded unwanted high frequency noise and the DC effect of gravity. This accelerometer and circuitry were mounted on a small board, about $2 \times 2 \times 1 \mathrm{~cm}$, and weighs $10 \mathrm{~g}$. The accelerometric sensor was placed on the lower part of the back (L4-L5 level). The sensor output was sampled at $40 \mathrm{~Hz}$ by a programmable logger ${ }^{\dagger}$. The root mean square (RMS) of the sampled signal was calculated on line each second and then stored in the memory of the data logger. RMS reflects the average amplitude of body acceleration. The data logger weighed $215 \mathrm{~g}$ and was worn on the side. In parallel, a high precision triaxial accelerometer ${ }^{\S}$ was used to verify the validity of the output of the first one. Accelerometers were piezoresistive sensors coupled with amplifiers $( \pm 5 \mathrm{~g}$, $500 \mathrm{mV} \mathrm{g}^{-1}$ ). The accelerometers, analogue filters, and amplifiers were mounted on a belt (same position as the uniaxial accelerometer) and the logger was worn on the side of the body. The signal was filtered at $17 \mathrm{~Hz}$, sampled at $40 \mathrm{~Hz}$, and stored in the logger before post-processing using a microcomputer (calculation of RMS each second).

Two THOMMEN HM30 meteorological stations ${ }^{\ddagger}$ were used as barometers to determine the vertical position of the subject. Pressure data were recorded every $5 \mathrm{~s}$ on the two devices. To obtain precise altitudes, not dependent on local variations of meteorological conditions, a differential method was used. The base station was installed at a point with known altitude. Barometric height differences were calculated using Laplace's formula every five seconds between the base station and the moving instrument. This algorithm (eqn 1) calculates the altitude difference using pressure measurements, and by adjusting the result with local average parameters.

$$
\begin{aligned}
& \Delta X=18376.03 \log \frac{p_{1}}{p_{2}}\left(\frac{t_{m}}{273.16}\right) \\
& \quad\left(1+0.378 \frac{r h_{m}}{p_{m}} 10^{c_{1}}\right)\left(1+\beta \cos 2 \phi_{m}\right)\left(1+\frac{2 H_{m}}{R}\right)
\end{aligned}
$$

where

$$
\begin{aligned}
\Delta X & =\text { altitude difference }[\mathrm{m}] \\
p_{1}, p_{2} & =\text { pressure at point } 1 \text { and } 2[\mathrm{mPa}] \\
c_{1} & =\text { corrective term related to temperature } t_{m}[\mathrm{~K}] \\
\beta & =\text { constant }=0.00264 \\
R & =\text { Earth radius } 6370000 \mathrm{~m} \\
H_{m} & =\text { mean altitude }[\mathrm{m}] \\
t_{m} & =\text { mean temperature }[\mathrm{K}] \\
r h_{m} & =\text { mean relative humidity }[\%] \\
p_{m} & =\text { mean local pressure }[\mathrm{mPa}] \\
\phi_{m} & =\text { mean latitude }[\mathrm{rad}] .
\end{aligned}
$$

\footnotetext{
*ADXL05, Analog Devices Inc., Norwood, MA, USA

$\dagger$ Tattletale Model 5F, Onset Computer Corp., Pocaset, MA, USA

$\S$ Physilog, BioAGM, Lausanne, Switzerland

$\$ \mathrm{CH}-4437$ Waldenburg, Switzerland
} 


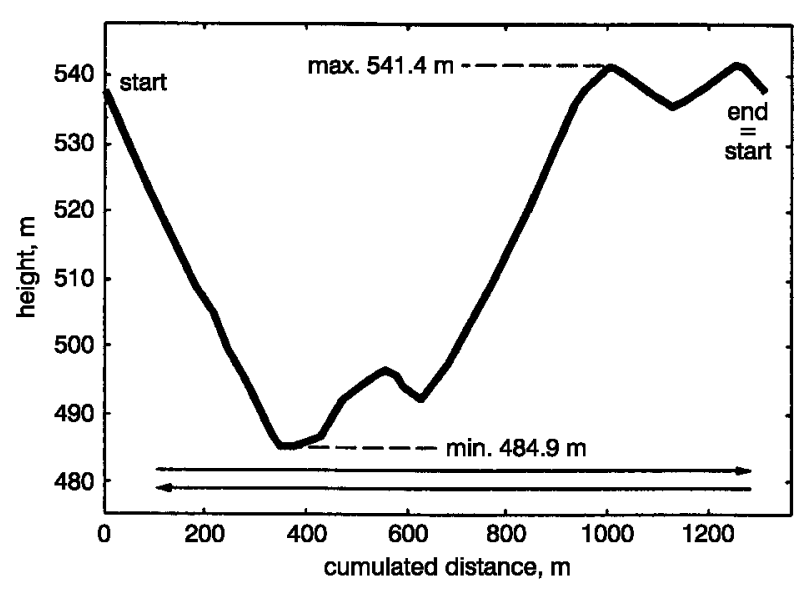

Fig. 1 Profile of the circuit. Variation of altitude with distance

With the purpose of eliminating possible bias between the two barometers, two short calibration periods were performed, one before and the other after the walk. During the test, air temperature was constantly recorded to obtain better accuracy. Past experiments have shown that, with this kind of equipment and method, it was possible to reach an altimetric accuracy of about 60 to $80 \mathrm{~cm}$ (PERRIN, 1999). Vertical speeds were derived from altitudes calculated using the Laplace formula. We interpolated the $5 \mathrm{~s}$ data with a second-order equation to obtain altitudes at $1 \mathrm{~Hz}$, so as to obtain the same sampling rate as the accelerometric and GPS devices. The instantaneous speed was then computed by dividing the exact variation of altitude by the time. The total weight of the instruments was about $5 \mathrm{~kg}$.

To minimise the impact of normal variations from one gait cycle to another, average speed (DGPS), average acceleration (RMS) and average altitude variation were calculated using two different approaches: first, average values were computed with a constant time interval of $10 \mathrm{~s}$ (moving average calculated for each $1 \mathrm{~Hz}$ point). This induced an estimated DGPS speed precision of $\pm 0.051 \mathrm{~km} \mathrm{~h}^{-1}$ for a subject walking at $4 \mathrm{~km} \mathrm{~h}^{-1}$. Second, to obtain values along a circuit section with constant incline, averages were calculated for each of the predetermined 36 sectors of the circuit with constant slope (estimated DGPS speed error: $<0.01 \mathrm{~km} \mathrm{~h}^{-1}$ ). The slope of the terrain in each of the 36 segments of the circuit run was calculated using DGPS data (vertical distance divided by horizontal distance). The correlation coefficient between the average vertical velocity provided by barometer and by surface slope (DGPS) was computed for each run for each subject ( 28 correlation coefficients).

For each subject, a linear regression was calculated for each run. The aim was to express the velocity measured by DGPS, first in terms of the acceleration (eqn 2) and then in terms of the acceleration and the vertical speed given by the altimeter (eqn 3):

$$
\begin{aligned}
& V_{G P S}=a_{1}+b_{1} \cdot R M S_{a} \\
& V_{G P S}=a_{2}+b_{2} \cdot R M S_{a}+c_{2} \cdot V_{A L T}
\end{aligned}
$$

where

$$
\begin{aligned}
V_{G P S} & =\text { velocity measured by DGPS } \\
R M S_{a} & =\text { root mean square (RMS) of the acceleration } \\
V_{A L T} & =\text { vertical velocity given by the altimeter } \\
a_{i}, b_{i} c_{i} & =\text { Coefficients of the regressions }
\end{aligned}
$$

Then the so-determined coefficients were applied to the second run of the subject in order to predict the speed of the person $\left(V_{P R E D}\right)$. Using this method, we had for each subject two values for each coefficient. Then it was possible to compute a Pearson's correlation coefficient between $V_{G P S}$ and $V_{P R E D}$.

All averaged data are presented as mean \pm standard deviation.

\section{Results}

RMS body acceleration in the anteroposterior direction, calculated with the two different accelerometers (uniaxial and triaxial), was very similar $(r=0.93 \pm 0.09)$. We were therefore confident in the reliability of the RMS value of body acceleration. The average Pearson's correlation coefficient between surface slope (DGPS) and vertical velocity (barometer) was high: $r=0.91 \pm 0.11$. Figs 2 and 3 show the improvement in speed prediction using the accelerometer plus altitude variation measurement for one typical subject. Values were averaged every ten seconds and predicted speed was calculated as described above. The accelerometer output alone does not match the speed variation of the subject (Fig. 2), but by adding the variation in altitude as a second predictive factor, a substantial improvement was found (Fig. 3).

Using the averaged values for the constant slope sections, it was found that for twelve subjects, that is, the large majority, a significant increase in correlation between $V_{P R E D}$ and $V_{G S P}$ appeared when combining acceleration with altitude variation. Only for two subjects did the use of the altimeter fail to improve significantly prediction of the speed. Before using altimetry, correlation was low (average $r=0.42 \pm 0.43$ ): with integration of the altimeter, one can see (Fig. 4) a significant improvement in correlation (average $r=0.70 \pm 0.11$ ).

The coefficients of the regressions (eqn 2 and eqn 3 ) varied substantially among the subjects. For instance, the average result for eqn 3 was: $V_{P R E D}=0.75 \pm 0.30 \mathrm{~m} \mathrm{~s}^{-1}+0.47 \pm$ $0.31 \mathrm{~g}^{-1} \cdot R M S_{a}-0.25 \pm 0.56 \mathrm{~s} \mathrm{~m}^{-1} \cdot V_{A L T}$.

The relative errors in speed prediction for each section of the circuit compared to GPS speed have been arranged according
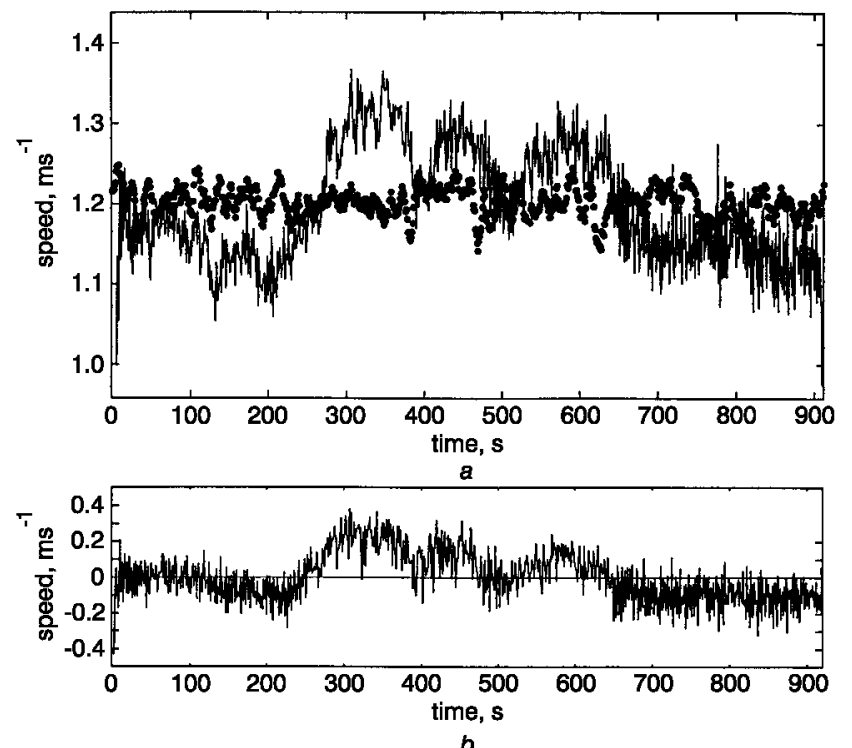

Fig. 2 (a) Typical case of speed prediction with the accelerometer only, at $1 \mathrm{~Hz}$ sampling rate averaged over $10 \mathrm{~s}$ (moving average calculated at each $1 \mathrm{~Hz}$ point). (b) Residuals (difference between actual and predicted speed). Correlation between measured $(\longrightarrow$ ) and predicted $(\bullet)$ speed: $\mathrm{r}=0.59$. The subject was a female age 21 , height $167 \mathrm{~cm}$, weight $65.0 \mathrm{~kg}$ including equipment 

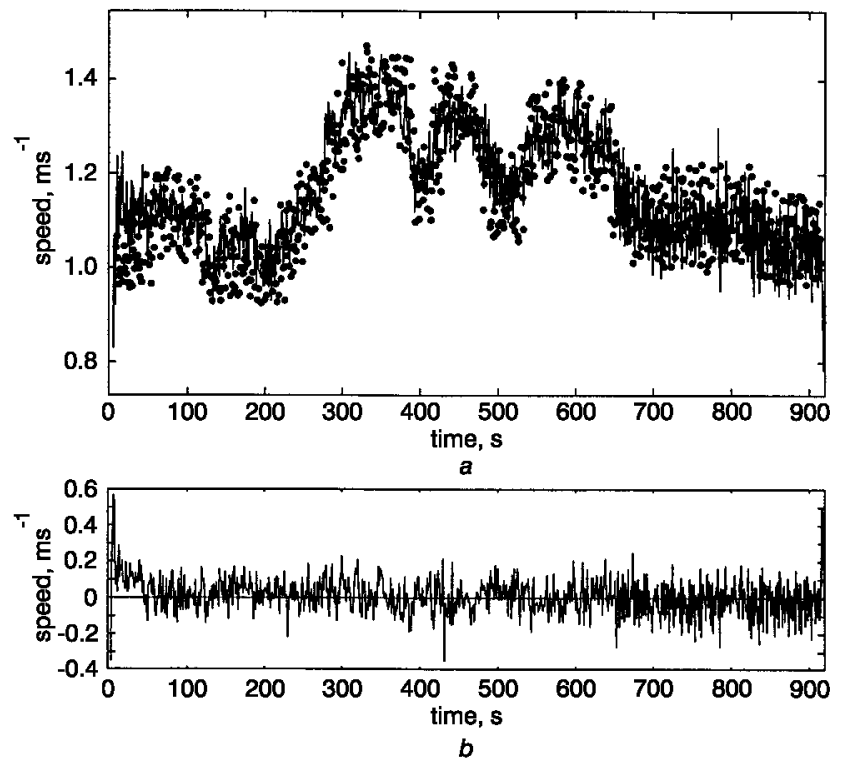

Fig. 3 (a) Tipical case of speed prediction with the accelerometer and the altimeter at $1 \mathrm{~Hz}$ sampling rate averaged over $10 \mathrm{~s}$ (moving average calculated at each $1 \mathrm{~Hz}$ point). (b) Residuals (difference between actual and predicted speed). Correlation between measured $(\longrightarrow$ and predicted $(\bullet)$ speed: $\mathrm{r}=0.93$. The subject was a female age 21, height $167 \mathrm{~cm}$, weight $65.0 \mathrm{~kg}$ inchuding equipment

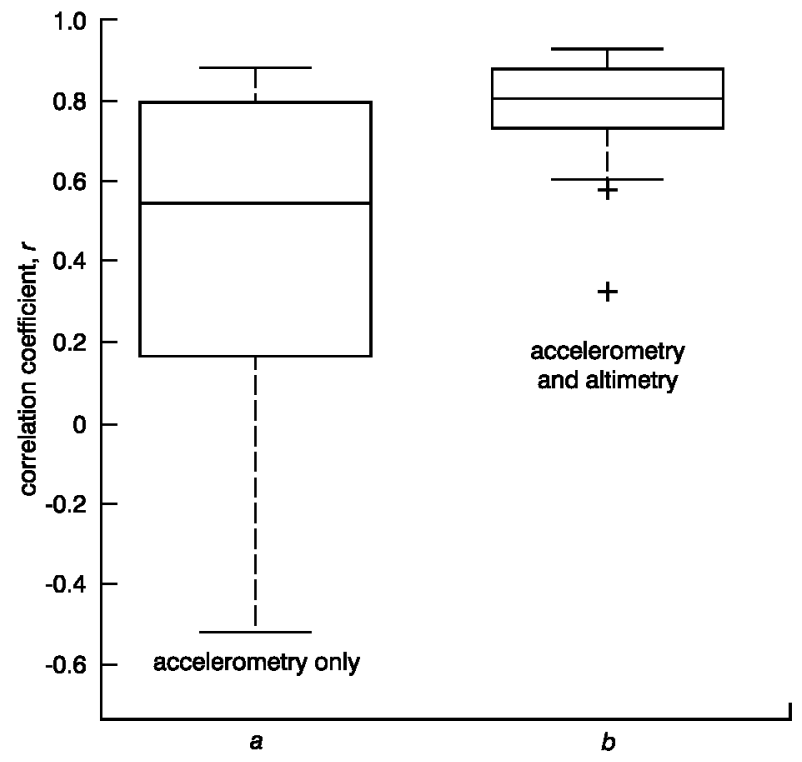

Fig. 4 Inter-individual variability of the correlation coefficient between the measured and the predicted speed with (b) and without (a) the use of altimetry $(\mathrm{N}=28)$. The box has lines at the median, lower $Q(25 \%)$ and upper $Q(75 \%)$ quartile values. The 'whiskers' are lines extending from each end of the bor to the smallest or the largest value situated inside the interval: $O(25 \%)-1.5 *(Q(75 \%)-Q(25 \%))$ and $Q(75 \%)+$ $1.5 *(Q(75 \%)-Q(25 \%))$. This shows the range of the data. Outliers (+) are data with values bevond the ends of the whisker's

to the slope of the section. Seven slope classes have been defined, with an interval of $5 \%$. The number of points in each class is not constant. Integration of the altimeter yields an improvement in speed prediction, particularly for high positive and negative slopes (Fig. 5).

To evaluate the need for calibration, two subjects did not carry out both runs on the same day, but two weeks apart, with very different meteorological conditions (cold and rain/very

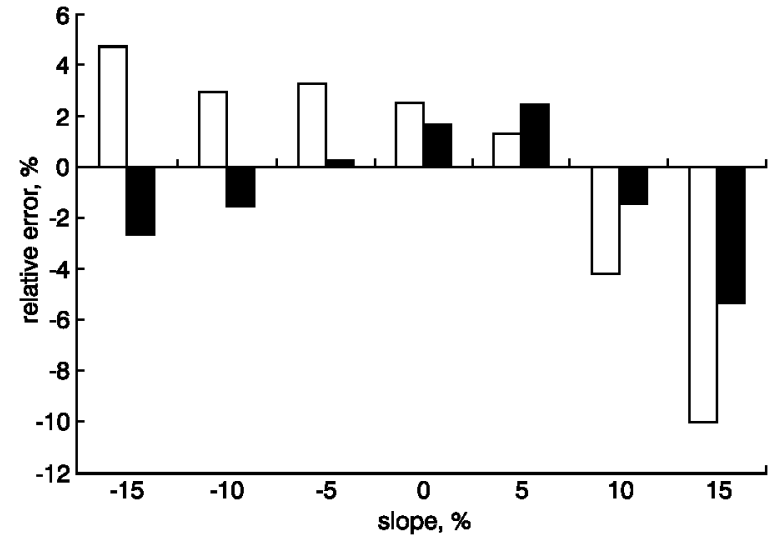

Fig. 5 Partition of the speed prediction relative error in terms of slope. Grev rectangles show the prediction error with accelerometer only: Black rectangles show the prediction error with altimeter and accelerometer.

hot and sunny). Relative errors in speed prediction (calculated as in Fig. 5) were very high. Without altimetry, they ranged between $-8.6 \%$ and $40.2 \%$. With altimetry, the relative error ranged from $-2.9 \%$ to $52.9 \%$. These errors were due to very different regression coefficients on the two runs.

\section{Discussion}

For a given body weight, energy expenditure while walking depends upon two principal parameters: slope and speed. In uphill walking, work is carried out against gravity, therefore the energy output is high (MINETTI et al., 1995). In downhill walking, a part of the potential energy is used to help the translation of the body, therefore energy expenditure is low (PIVARNIK and SHERMAN, 1990). Increasing speed requires a longer step and/or a higher step frequency, involving greater muscular activity. The relationship between speed, slope and energy expenditure has been well known since the early 1960s (BOBBERT, 1960).

Slope assessment during walking can be carried out by measuring altitude variation. We found high correlation $(r=0.91)$ between altitude variation (barometry) and slope as calculated by DGPS. This promising result indicates that it could be possible to develop a predictive algorithm for slope variation during walking. It was also observed that the combination of altitude variation measurement with acceleration measurement improve significantly the speed prediction of human locomotion $(r=0.70)$. This simple linear predictive algorithm needs to be improved and more accurate results should be obtained in the future. Because speed and slope are the main factors involved in the energy cost of locomotion, the prediction of energy expenditure when walking can be considered under variable slope conditions.

Inter-individual variation of the human walking mechanics has recently been pointed out (BIANCHI et al., 1998). Each subject may adopt a different strategy in her/his mechanical energy management, for example by limiting the amplitude of energy oscillations of the main body segments, or by conserving more energy by means of a transfer between the trunk and the lower limbs. Individual differences in the adaptation of stride length, stride frequency and walking speed to slope variation were also described (SUN et al., 1996). It is obvious that these biomechanical differences between subjects influence body acceleration and therefore modify regression coefficients for speed prediction. Consequently, a wide range of regression coefficients linking acceleration/altitude variation 
and walking speed was found among subjects in our study. Moreover, we observed that intra-individual variation occurred if the two circuits were performed in very different meteorological conditions, indicating that external factors influence the style of walking, probably in terms of a different adaptation of speed/stride frequency/stride length to slope.

To circumvent the variability of the acceleration/altimeter/ speed relationship, individual calibration is necessary as often as possible. A device combining DGPS with accelerometer and altimeter could be an elegant solution: DGPS could be used to recalculate a predictive model when the satellite signal is available, and the accelerometer/altimeter could be used to assess speed and slope in conditions of no access to satellites.

The use of DPGS for human locomotion studies opens up new perspectives in the field of biomechanics and physiology. Indeed, until now, it has been impossible to assess the speed and position of a person during outdoor walking with such a high accuracy and so few constraints. New GPS devices are user-friendly and can be used with minimal training. For a 50$\mathrm{m}$ walk at normal speed, the precision in position and time allows an average speed accuracy of $0.03 \%$ which is comparable with the accuracy that a photoelectric system can provide: one should remember that GPS time is based on an atomic clock network. The main advantage of GPS is that it is possible to follow the movements of a subject under totally unconstrained conditions, provided the antenna can receive the satellite signal. The subject has total freedom in the choice of walking style and can follow any preferred pathway. This is more comfortable and nearer an actual physiological situation than current laboratory treadmill experiments. By combining GPS with a portable indirect calorimeter device, it might be possible to obtain outdoor data on the energy cost of walking in terms of speed and slope, with no constraint on the subject other than wearing a backpack and face mask.

Acknowledgments - The authors would like to thank J.M. Schedel and V. Gabaglio for their technical assistance.

\section{References}

Almeras, N., Mimeault, N., Serresse, O., Boulay M. R., and TREMBLAY, A. (1991): 'Non-exercise daily energy expenditure and physical activity pattern in male endurance athletes', Eur: J. Appl. Physiol., 63, pp. 184-187

Balogun, J. A., Martin, D. A., and Clendenin, M. A. (1989): 'Calorimetric validation of the Caltrac accelerometer during level walking,' Phys Ther:, 69, pp. 501-509

BIANCHI L., ANGELINI D., and LACQUANiTI, F. (1998): 'Individual characteristics of human walking mechanics,' Pflugers Arch., 436 pp. 343-356

BobBERT, A. C. (1960): 'Energy expenditure in level and grade walking', J. Appl. Physiol., 15, pp. 1015-1021

Eston, R. G., Rowlands, A. V., and INGLEDEw, D. K. (1998): 'Validity of heart rate, pedometry, and accelerometry for predicting the energy cost of children's activities,' J. Appl. Physiol., 84, pp. $362-371$

Hakim, A. A., Petrovitch, H., Burchfiel, C. M., Ross, G. W., Rodriguez, B. L., White, L. R., Yano, K., Curb, J. D., and Аввотт, R. D. (1998): 'Effects of walking on mortality among nonsmoking retired men', New England J. Med.. 338, pp. 94-99

LEICK, A. (1995): 'Satellite surveying', 2nd Edn (Wiley-Interscience, John Wiley \& Sons Inc., New York)
Mejer, G. A., Westerterp, K. R., Koper, H., and Ten Hoor, F. (1989): 'Assessment of energy expenditure by recording heart rate and body acceleration', Med. Sci. Sports Exerc., 21, pp. 343-347

Melanson, E. L. JR., and FreEdson, P. S. (1995): 'Validity of the Computer Science and Applications, Inc. (CSA) activity monitor', Med. Sci. Sports Exerc., 27, pp. 934-940

MNETTI, A. E. (1995): 'Optimum gradient of mountain paths', $J$. Appl. Physiol., 79, pp. 1698-1703

Montoye, H. J., WAshburn, R., Servais, S., ERTL, A., Webster. J. G., and NAGLE, F. J. (1983): 'Estimation of energy expenditure by a portable accelerometer', Med. Sci. Sports Exerc., 15, pp. 403-407

Pate, R. R., Pratt, M., Blair, S. N., Haskell, W. L., Macera. C. A., Bouchard, C., Buchner, D., EtTinger, W., Heath, G. W., KING, A. C. (1995): 'Physical activity and public health: a recommendation from the Centers for Disease Control and Prevention and the American College of Sports Medicine', J. Am. Med. Assoc., 273, pp. $402-407$

PERRIN, O. (1999): 'Intégration de mesures satellitaires et barométriques pour la localisation 3D', Mensuration, Photogrammétrie, Génie rural, 6/99, pp. 320-323

PiVARNIK. J. M., and SHERMAN, N. W. (1990): 'Responses of aerobically fit men and women to uphill/downhill walking and slow jogging', Med. Sci. Sports Exerc., 22, pp. 127-130

SCHUTZ, Y., and ChamBaZ, A. (1997): "Could a satellite-based navigation system (GPS) be used to assess the physical activity of individuals on earth?' Eur. J. Clin. Nutr:, 51, pp. 338-339

SchuTz, Y., and Deurenberg, P. (1996): 'Energy metabolism: overview of recent methods used in human studies', Ann. Nutr: Metab., 40, pp. 83-93

Sun, J., Walters. M. SVENsson, N., and Lloyd, D. (1996): 'The influence of surface slope on human gait characteristics: a study of urban pedestrians walking on an inclined surface', Ergonomics, 39, pp. 677-692

TERRIER, P., AMINIAN, K., and SchUTZ, Y. (1999): 'Can accelerometry accurately predict energetic cost of walking in uphill and downhill conditions?' Int. J. Obes. Relat Metab. Disord., 23, Supp1 5, p. S60

\section{Authors' biographies}

OLIVIER PERRIN graduated from the Swiss Federal Institute of Technology (EPFL) in 1999 as geodetic surveyor. He works in Australia, dealing with different positioning activities.

PhILIPPE TERRIER is a PhD student who graduated in biology at the University of Lausanne in 1995. In 1997 he obtained a diploma in biomedical engineering at the Swiss Federal Institute of Technology. His research projects deal with new methods to study energy expenditure induced by locomotion.

QUENTIN LADETTO is undertaking a PhD at EPFL in collaboration with the Institute of Physiology of Lausanne University. His research focuses on the particularities of INS (Inertial Navigation System) GPS integration for human, on-foot navigation.

BERTRAND MERMINOD has been a professor at the Geodetic Engineering Laboratory (EPFL) since 1995. He earned his MSurv at the University of New South Wales (Australia) in 1989 before working as Geodetist and Manager in Lesotho for the Swiss Development Cooperation. He was product manager with Leica AG from 1993 to 1995.

YvES SCHUTZ received his PhD from the University of California in Berkeley (USA) and is currently a lecturer in physiology at the Faculty of Medicine (University of Lausanne). His interests relate to the relationship between physical activity and health. 